\title{
Analysis and Improvement of an Innovative Solution Through Risk Reduction: Application to Home Care for the Elderly
}

Linda Acosta-Salgado ${ }^{*}$, Auguste Rakotondranaivo, Eric Bonjour

Research Team on Innovation Process (Laboratoire ERPI, EA $N^{\circ}$ 3767), Université de Lorraine, Nancy, France

\begin{tabular}{l} 
A R T I C L E I N F O \\
\hline Article history: \\
Received: 17 January, 2020 \\
Accepted: 27 March, 2020 \\
Online: 08 May, 2020 \\
\hline
\end{tabular}

Keywords:

Acceptability

Acceptance

Need

Risk

Elderly care

Healthcare innovation

\begin{abstract}
A B S T R A C T
The increase in the number of elderly people requires multiple efforts to maintain their well-being and health. A wide variety of products and services have been created to enable seniors to live at home for as long as possible. The market success of these solutions depends on acceptance by the different stakeholders. Older people are reluctant to change their environment, most notably their home. Solutions must provide a benefit and/or reduce risks related to their everyday life in order to be accepted. Design methods are mainly focused on needs analysis, while acceptability assessment models are based on the study of benefits. A need may also correspond to a risk that may be present in the initial situation and that has to be eliminated or reduced. The notion of risk is not sufficiently integrated in these models. This paper proposes a new approach to analyze the actual situation of elderly people at home based on risk analysis. The objective is to contribute to the design of solutions that will be more readily accepted by this population. A model for estimating the risk of falling has been proposed. The probability of two elderly people falling in their home is assessed using this model. The design and improvement of solutions are explored using the results obtained.
\end{abstract}

\section{Introduction}

The ageing of the world's population is a key issue for the years to come. Demographic trends reveal an increasing proportion of older people and rising life expectancy. According to projections made by the National Institute of Statistics and Economic Studies (INSEE), in 2070, France should have 76.5 million inhabitants, 10.7 million more than in 2013. Specifically, the population aged 65 and over should increase by 11.2 million and those aged 20-64 decrease by 7.9 million [1]. Thus, by 2070 , there will be more seniors than younger people to help them. This situation confronts the health field with a major societal challenge: delaying the age of entry into dependency and improving the well-being of the elderly by controlling risks and expenditure [2].

Public policy encourages the creation of new products and services for keeping people at home as long as possible. For the private industrial and commercial sectors, ageing represents an economic opportunity. Technology companies see this segment of the population as an attractive market for products and services that are easy to use and affordable [3]. In recent years, many

*Corresponding Author: Linda Acosta-Salgado, Université de Lorraine, Nancy, France. Email: linda.acosta-salgado@univ-lorraine.fr technological and organizational innovations have been developed to improve elderly home care. These include video-vigilance systems, fall detectors, tele-assistance and home automation equipment.

Innovative solutions for the ageing population could increase elderly people's capabilities and help them to reduce their entry into dependency by transforming their living environment [4]. Hence, they have to satisfy the needs and preferences of multiple stakeholders (older people, their families, caregivers, care structures, etc.). However, these stakeholders are not always in favor of integrating changes into their daily lives [5].

The success of an innovative project is evaluated by its acceptability in the design phase and by its acceptance in the use phase [6]. To promote the acceptance of a product or service, it is necessary to accompany its design process, from the early stages, by evaluating its acceptability [7]. To improve innovation acceptance, the project must provide benefits and/or reduce the risks perceived by its future users.

In order to improve the well-being of older people at home and increase the likelihood that innovative solutions will be accepted by their various users, it is important to integrate the notion of risk 


\section{L.A. Salgado et al. / Advances in Science, Technology and Engineering Systems Journal Vol. 5, No. 3, 158-165 (2020)}

into the design and improvement process of solutions. The recognition of the positive and negative points of a situation leads design teams to imagine new products and develop new ways of proceeding [8]. Within this framework, this article proposes an analysis approach for improving innovative solutions based on risk analysis of the real situation of elderly people staying at home.

This paper is an extension of work presented in the International Conference on Engineering, Technology and Innovation (ICE/ITMC) [7]. The approach proposed for analyzing and improving a solution based on its risk study is more detailed. After this introduction, the second section presents a literature review on design methods, acceptability assessment models and risks for older people living at home. The next section proposes a conceptual approach and a model to evaluate the risk of falling. It also describes the methods and materials used to assess the fall risk of two people living in their own home. The fourth section presents the results and explores the value of addressing these results to improve a solution. The final part presents the discussion, conclusions and research perspectives.

\section{Literature Review}

\subsection{Design Methods}

The notion and discipline of design has been in constant evolution [9]. The development of new products was initially based on the search for function-based solutions. Over time, user needs were seen as a determining factor in the design process, and several user-centered design currents have developed in recent decades.

Today, design approaches such as user innovation, user experience, emotional design and design thinking, seek to better understand the needs of users and conceive new solutions alongside them [10]. Different design stages have been proposed as well as different ways of identifying them [11]. Generally, these processes include phases for understanding the problem, defining the design project, finding solutions, prototyping and evaluation. At the end of this process, the expected results boost the acceptability of the new solutions.

In various design models, the notion of need is fundamental. Need can be defined as a desire resulting from a lack or a dissatisfaction in the goal achievement process [12]. It is relative to an individual and is perceived differently by each person. Need perception can also be the product of risk perception. This need consists in eliminating or reducing the severity or the probability of occurrence of this risk.

\subsection{Acceptability Assessment Models}

A lot of research has been carried out to assess the acceptability and acceptance of innovative solutions. Researchers have proposed different theoretical models such as the Theory of Reasoned Action (TRA) [13], the Theory of Planned Behavior (TPB) [14] and the Technology Acceptance Model (TAM) [15]. These models have been modified several times by incorporating new factors and relationships between them [16].

The changes made to these models have been aimed at adapting them to evaluate specific innovations in a given context (actors, uses) and in a particular field. Many models have been created in this way, such as TAM 2, TAM 3 and UTAUT.

A literature review of models used in the health field [7] revealed that most existing models are not suitable to assess acceptability at the design stage or to incorporate the preferences of multiple stakeholders. In these models, the assessment is mainly based on the analysis of factors such as utility and ease of use. The review identified only a few studies that incorporate "perceived risk" as a factor in acceptance assessment models [17-19]. No documents were identified proposing a risk-based approach to improve an innovative solution or to design new concepts.

\subsection{Risks for Elderly People at Home}

Risks can be defined as people's feelings about the potential negative consequences of a situation [20] that may prevent goal achievement. Risk perception is a decisive variable in the choice of behavior [21]. Understanding and managing risk is linked to innovation. Awareness of risks and their factors is a necessary condition for making intelligent decisions in innovation [8]. They are both a threat to the success of a project and an opportunity to make improvements.

Different approaches have been used to diagnose the risks faced by older people at home [22-24]. A literature review conducted by Stuck presents a list of risks of declining functional status for older adults living at home [25]. However, these risks focus on the biological aspects of elderly people such as physical and mental health and social aspects. Other studies have identified additional risks that take into account the impact of the environment on the well-being of elderly people living at home [26-28].

In a previous study [7], risk identification regarding elderly people at home was carried out. This was done through a literature review and the application of expert interviews. Twenty-two risks were identified and classified into eight categories (figure 1).

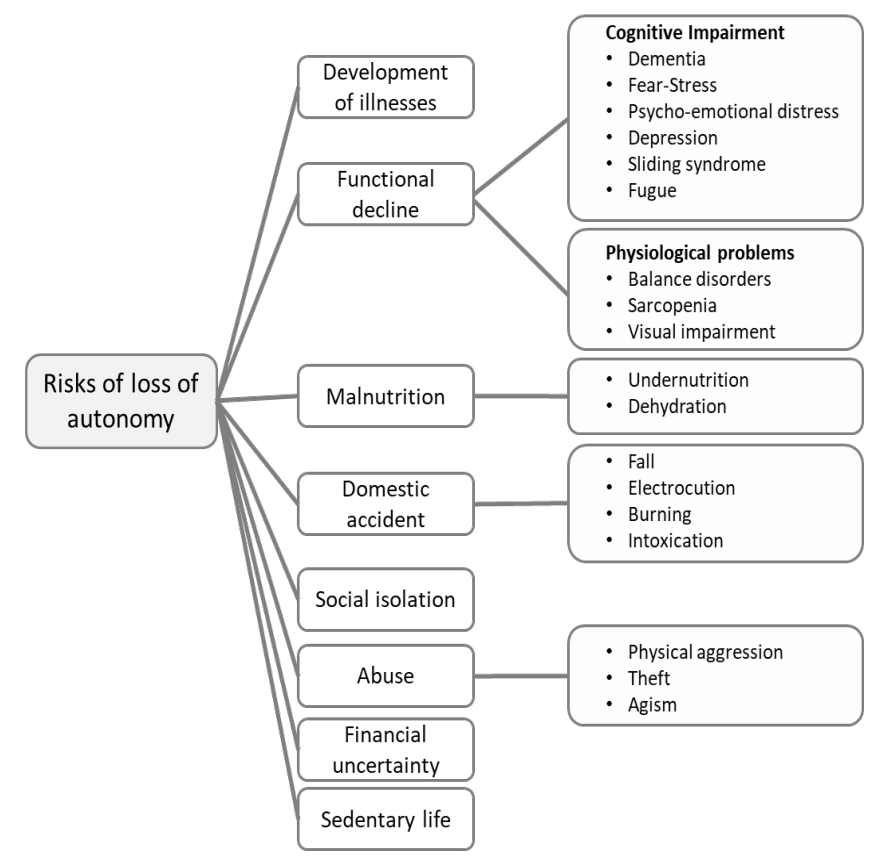

Figure 1: Risks to the elderly at home 


\section{L.A. Salgado et al. / Advances in Science, Technology and Engineering Systems Journal Vol. 5, No. 3, 158-165 (2020)}

The occurrence of such risks is a determining factor in the deterioration of elderly people's well-being and endangers their ability to stay at home. If one of these risks is detected, it could influence the occurrence of others in a systematic way. In order to estimate the likelihood of a risk occurring, it is necessary to identify the causal factors.

\subsection{Risk of Falling}

Falls are among the most common and serious problems, the consequences of which mainly affect individuals (functional decline, morbidity, institutionalization, mortality, etc.) and the health system [29]. Most falls by the elderly are the result of interactions between intrinsic (physical and cognitive) and extrinsic (socio-economic and environmental) factors [30]. The identification of risk factors for falls among older adults living at home has been the subject of several studies [31-34]. They have shown that the risk of falling increases as the number of risk factors increases.

\section{Material and Methods}

\subsection{Approach for Analyzing and Improving Innovative Solutions}

This article's assumption is that the notion of risk can contribute to the understanding of a problem situation and impact upon the design of innovative solutions. It may enrich the process of needs analysis as well as the evaluation and improvement of proposed solutions. The approach is depicted in Figure 2.

In the proposed approach, three stages of the design process are considered. The first step is the exploration of the problem. At this stage, different stakeholders (funders, project managers, future users, regulatory institutes) are involved in the needs analysis. Using different engineering and design tools, risks, lacks, dissatisfactions and desires are explored to analyze needs. Thus, the design objective and specifications can be defined to guide the design team in proposing solutions.

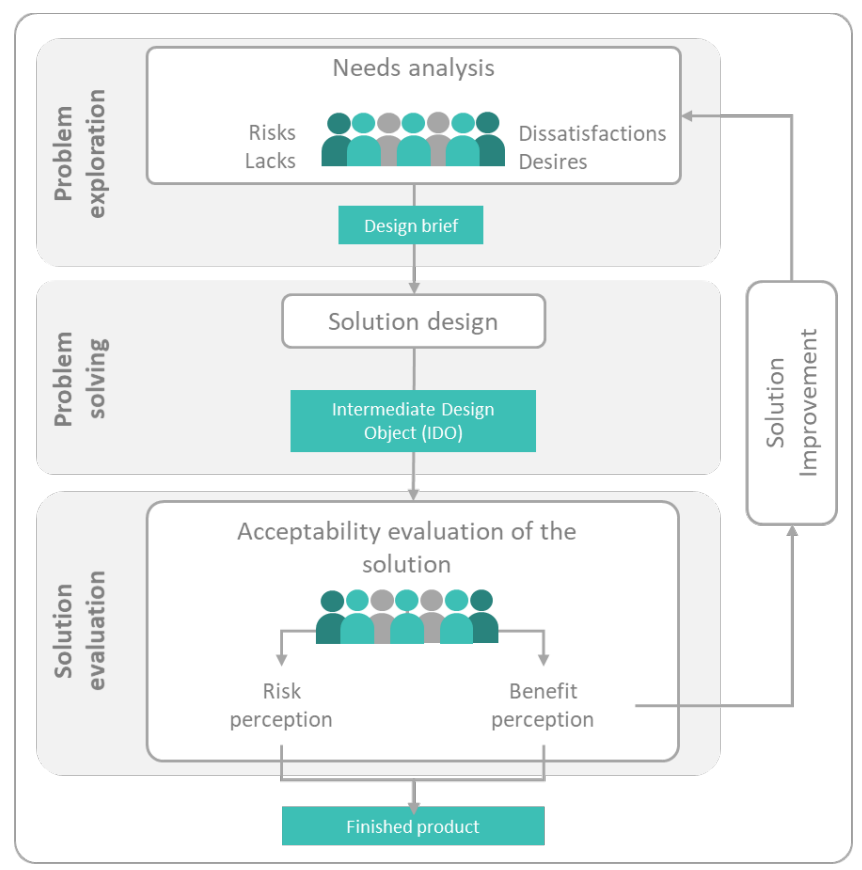

Figure 2: Approach proposed to analyse and improve an innovative solution.
The second step is the resolution of the identified problem. Here, different methods are used for the ideation and prototyping of solutions. In the first step, multiple creativity sessions are carried out in order to outline the design possibilities. Subsequently, an alternative solution is chosen and is then further designed. Different intermediate design objects (ICOs) are developed to communicate and validate the characteristics assigned to the solution. ICO is a partial outcome of the project, such as a schematic, a scale model, or a prototype [35]. The objective is to represent a part or the whole of the proposal in order to evaluate it with users and further develop the product.

The third step, solution evaluation, is an important stage in the design process. It allows the solution concept to be tested with future users to identify the benefits and risks they perceive relative to using this concept. In this way, the acceptability of a solution can be estimated. The result of this evaluation brings elements of improvement (to reduce the perceived risks and/or increase the benefits), which can be considered in the problem understanding and in the specification redefinition. This advanced understanding of the problem will allow designers to refine their proposals and better respond to it. We believe that successive evaluations of the solution and integration of gradual improvements would lead to an increase in acceptability. Thus, at the end of the design phase, the final product would have a higher probability of market acceptance.

The next section will apply this approach to the context of home care for the elderly. When we explored the problem of loss of autonomy among the elderly, the choice was made to apply the approach to the risk of falling. This risk has a high probability of occurrence and its consequences are severe.

\subsection{Model for Risk Assessment Using Bayesian Networks - Risk of Falling}

In order to estimate the probability of elderly people falling at home, we looked for a useful tool to assess the influence between factors and to determine the probability of occurrence. In the scientific literature, statistical methods are often used; however, they are insufficient for the evaluation of imprecise data from various sources. Recently, [36] used the Bayesian network modelling technique to estimate the probability of innovation acceptance based on an analysis of the influence of various factors. Among existing data modelling and analysis techniques, Bayesian networks are the most suitable for knowledge acquisition, representation and manipulation [37]. This technique makes it possible to reason about a problem by evaluating the causality between factors and sub-factors. In addition, it can be used to process uncertain information from different sources: expert knowledge, questionnaire data or the literature.

Bayesian networks have already been used for fall risk analysis $[38,39]$. However, the work carried out to date has not sought to be part of an approach to design and improve innovative solutions.

This article proposes to use this technique to assess the probability of elderly people falling at home. It is also assumed that Bayesian networks can be used to make a wider and overall risk assessment of this population.

The construction of the Bayesian network for estimating the risk of falling was carried out following the steps proposed by 
[37]. The first step consists in identifying the risk factors and the statuses that each of them may have. The second is the definition of the Bayesian network structure and the third is the construction of conditional probability tables.

\subsection{Identification of Risk Factors}

In the first stage, factors were identified mainly through the literature on the risk of falling [30-32,34,40-42]. A list was prepared and presented to an expert gerontologist and two researchers who analyzed and classified these factors (Table 1). Next, two possible statuses were defined for each factor: "yes" and "no". These statuses represent the variables of interest, in other words, the variations that each of the factors may present.

\section{Table 1: Fall Risk Factor Codes}

\begin{tabular}{ll}
\hline Code & \multicolumn{1}{c}{ Factor description } \\
\hline AG & Age \\
GD & Gender \\
HF & Fall historic \\
PP & Physiological problems \\
PP1 & Balance disorders \\
PP2 & Visual impairment \\
PP3 & Orthostatic hypotension \\
CI & Cognitive impairment \\
CI1 & Syncope \\
CI2 & Dementia \\
CI3 & Depression \\
SI & Social isolation \\
SI1 & Loss of social and family ties \\
UL & Unhealthy lifestyle \\
UL1 & Alcohol consumption \\
UL2 & Malnutrition \\
UL3 & Lack of physical activity \\
IE & Inadequate environment \\
IE1 & Inadequate objects \\
IE2 & Inadequate configuration of the living environment \\
MP & Medication problem \\
MP1 & Poly medication \\
MP2 & Taking psychotropic drugs \\
&
\end{tabular}

\subsubsection{Definition of the Bayesian Network Structure}

To build the structure of the network, a first proposal of links between factors was made based on the literature consulted. This structure was evaluated and improved with the experts. The final structure is shown in Figure 3. The network is made up of nodes, which correspond to the different factors and sub-factors. These nodes are linked by arcs that represent the causal and conditional dependence between them and the risk to be assessed. The factors have been classified into six groups: physiological problems, cognitive impairment, social isolation, unhealthy lifestyles, inadequate environment and medication problems. Each group is linked to between two and six factors. Four of these factors are related to more than one group: age, gender, history of falls and social isolation.

\subsubsection{Construction of Conditional Probability Tables}

Conditional probability tables are used to estimate the occurrence probability of one of the node statuses as a function of the parent nodes statuses [37]. A first version of the tables has been proposed from the literature consulted. The information obtained was supplemented by the experts, who used their experience and knowledge to define probability values between factors.
The final version of the network structure and the conditional probability tables by risk factor were modeled using the GeNIe Academic software.

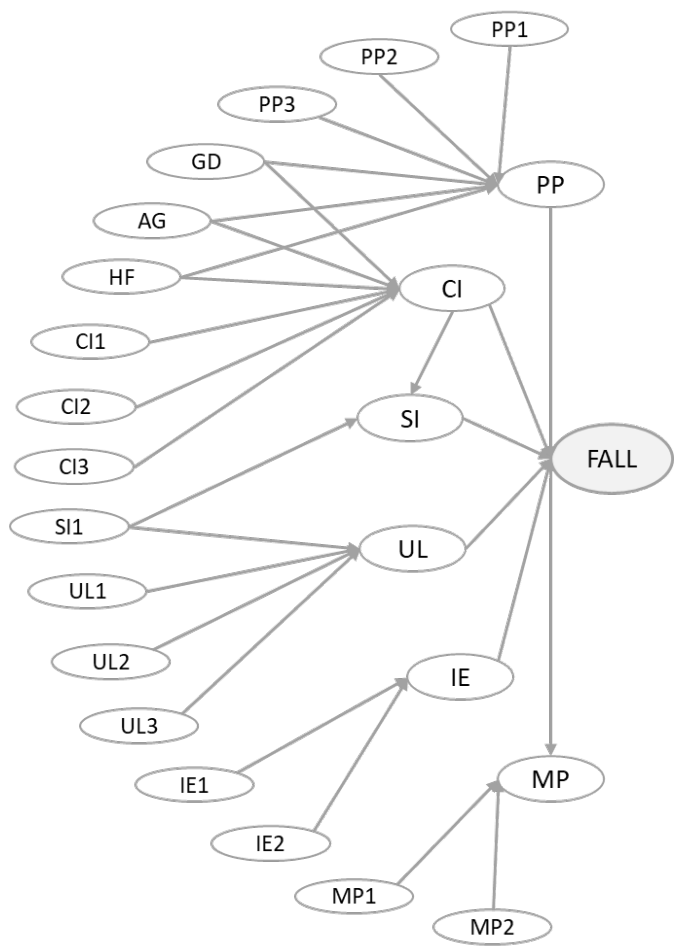

Figure 3: Bayesian network model of home falls risk

\subsection{Data Collection Method}

In order to make a first assessment of the probability of falling among older people, the proposed model was used. The data collection method chosen was the semi-directive interview. Interviews are one of the most commonly used methods in field studies to collect information about people's perceptions and preferences in light of their experiences [43]. The semi-directive interview serves to guide the discussion with the interviewee based on a list of themes rather than on direct questions [44].

A semi-directive interview guide was constructed. Following the recommendations of [44], the guide was composed of a list of themes related to the perception of exposure to the different risk factors of the model.

An older couple living independently in their home was selected for interview. Ms. M, 91 years old, and her husband Mr. A, 95 years old, have been married for 70 years. They have been retired for more than 30 years and wish to continue to live in their own home. These people were chosen because of their advanced age and their interest in continuing to live autonomously and safely in their home.

With the consent of these two persons and their children, the interviews were conducted at home. Two members of the research group participated in the development of the interview. One of the researchers led the discussion with each person, while the second researcher wrote down his observations on the development of the interview and on the characteristics of the household. The interviews were recorded and subsequently transcribed. 

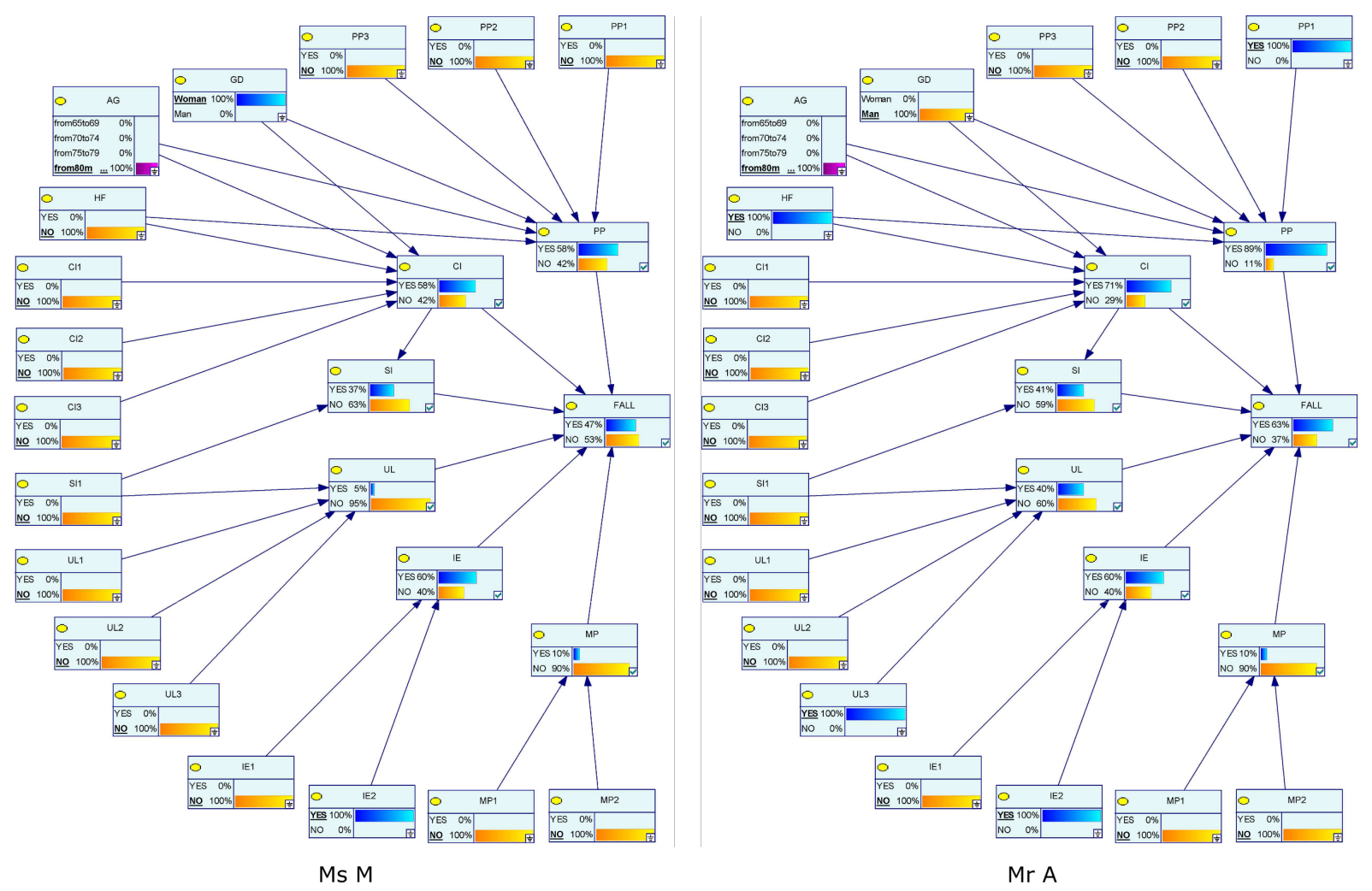

Figure 4: Fall risk estimation for Ms. M and Mr. A.

These elderly person's perception of the absence or presence of each of the risk factors was interpreted and coded according to the two conditions designated for each factor, namely, yes or no. The results obtained were introduced into the proposed Bayesian network.

The results obtained and the proposed Bayesian network were subsequently used to explore their use in the design and improvement of an innovative solution.

\section{Results}

\subsection{Fall Risk Assessment in the Problem Exploration}

In the interview, Ms. M declared that she has no physiological or cognitive problems. She does not consider herself to be in a situation of isolation since she has a large family and maintains strong relationships with them. She says that she does not have any health problems because she eats well, is very active and does not drink alcoholic beverages. In addition, she has home help to prepare meals, clean and care for her. She does not use psychotropic drugs and she does not take multiple medication.

Mr. A, in contrast to Ms. M, was to the victim of a serious fall in the house's bathroom a few months before the study. After this fall, several modifications were made to the bathroom by the family. However, Mr. A says he has difficulty moving around the house due to the "fear of falling again". This situation has increased his balance problems and decreased his physical activity.

In the observation we remarked that in fact several devices have been installed in the bathroom and in other parts of the house, such as in the bedroom and on the stairs. However, there are areas that may represent a risk: the floors are not non-slip in the kitchen, corridors and bedroom. Bathroom doors open inwards and locks cannot be opened from the outside. There are no brackets or grab bars in the corridors. They have a remote assistance system, which is installed in the master bedroom, but it cannot be used in the rest of the house.

The information obtained for Ms. M and Mr. A was synthesized in Table 2. Subsequently, this was entered into the Bayesian network and the probability of each person falling was estimated.

Figure 4 shows the networks per person. The existence of a risk factor is represented by the color blue and its absence by the color yellow. For the "age" factor, four bands were used, each represented by a different color.

Table 2. Response by factor

\begin{tabular}{|c|c|c|}
\hline & $\begin{array}{l}\text { Ms. M } \\
\text { AG: } 91 \text { years old } \\
\text { GD: woman }\end{array}$ & $\begin{array}{l}\text { Mr. A } \\
\text { AG: } 95 \text { years old } \\
\text { GD: man }\end{array}$ \\
\hline $\mathrm{HF}$ & No & Yes \\
\hline PP1 & No & Yes \\
\hline PP2 & No & No \\
\hline PP3 & No & No \\
\hline CI1 & No & No \\
\hline CI2 & No & No \\
\hline $\mathrm{CI} 3$ & No & No \\
\hline SI1 & No & No \\
\hline UL1 & No & No \\
\hline UL2 & No & No \\
\hline UL3 & No & Yes \\
\hline IE1 & No & No \\
\hline IE2 & Yes & Yes \\
\hline MP1 & No & No \\
\hline MP2 & No & No \\
\hline
\end{tabular}




\section{L.A. Salgado et al. / Advances in Science, Technology and Engineering Systems Journal Vol. 5, No. 3, 158-165 (2020)}

In Ms. M's network, we can identify that the biggest risk factors are inadequate environment (60\%), physiological disorders (58\%) and cognitive impairment $(58 \%)$, followed by social isolation (37\%). The two other factors, lack of hygiene (5\%) and medical problems $(10 \%)$ are not as representative. Analysis of these factors yields a $47 \%$ probability of falling.

In Mr. A's network, the results are different. The risk factors for physiological $(89 \%)$ and cognitive $(71 \%)$ problems are very significant. This significance is probably a consequence of the fall he had previously experienced, which caused him balance problems. It may also have been due to the likelihood of isolation risk (41\%) and poor hygiene ( $40 \%)$. The occurrence probability of the risk factors "unsuitable environment" $(60 \%)$ and "medication problems" (10\%) were no different from Ms. M's results since they live in the same house. Analysis of these factors results in a greater likelihood of falling, corresponding to $63 \%$.

\subsection{Design and Improvement of Innovative Solutions}

Using Bayesian networks, the proposed model estimated the probability of two elderly people falling in their homes. An extended model could be useful to detect different risks. On the one hand, the identification of the risk of falling may help project managers to better understand the needs of this population and to define specifications for proposing solutions. On the other hand, based on the risk factors identified, a design team can define areas for improvement of an innovative design solution. These two perspectives for using the results will be explored below.

\subsubsection{Designing Innovative Solutions}

A variety of solutions can be proposed to reduce the probability of the risk of falling. Some proposals may focus on increasing the person's mobility capabilities according to the characteristics of their home. Other solutions could consist in adapting the living space to the person's abilities.

In the case of Mr. A, who has a high risk of falling, the biggest risk factors are: walking and/or balance disorders, poor configuration of the living space and lack of activity. We imagined a new concept of an exoskeleton that adapts to the person's morphology to help him or her move around at home. In order to find out whether this technology could be accepted by its future users, the perceived risks could be evaluated.

\subsubsection{Improvement of an Innovative Design Solution}

If an innovative solution is not acceptable, the risks identified could provide insights for improvement. For example, if we take the exoskeleton and assume that future users do not accept this technology, then based on the analysis of the risk of falling, some changes could be made. The impact of these improvements on the reduction of the fall probability can be estimated with the Bayesian network.

Table 3 summarizes the different fall probabilities for Ms. M and Mr. A when introducing the exoskeleton and incorporating modifications to it.

For Mr A, the introduction of the exoskeleton could reduce the probability of falling by $4 \%$. However, if improvements are made to the solution to adapt it to the environmental conditions, such as a contact surface adaptable to floor characteristics, then the risk of falling could decrease to $54 \%$. In addition, if the exoskeleton incorporates a robotic system to help maintain balance, change posture and move around, then Mr. A's level of physical activity will improve and, as a result, the probability of falling can be reduced to $50 \%$. These improvements could reduce not only the risk of falling but also general risk perception. As a result, the acceptability of exoskeletons may increase.

Table 3 . The probability of falling after improvements

\begin{tabular}{|c|c|c|}
\hline & $\begin{array}{l}\text { Fall } \\
\text { probabilities } \\
\text { for Mr. A }\end{array}$ & $\begin{array}{l}\text { Fall probabilities } \\
\text { for Ms. M }\end{array}$ \\
\hline Initial situation & $63 \%$ & $47 \%$ \\
\hline Exoskeleton & $59 \%$ & \multirow{4}{*}{$43 \%$} \\
\hline $\begin{array}{l}\text { Exoskeleton with adaptable } \\
\text { contact surface }\end{array}$ & $56 \%$ & \\
\hline $\begin{array}{l}\text { Exoskeleton with robotic } \\
\text { system }\end{array}$ & $54 \%$ & \\
\hline $\begin{array}{l}\text { Exoskeleton with adaptable } \\
\text { contact surface and robotic } \\
\text { system }\end{array}$ & $50 \%$ & \\
\hline
\end{tabular}

In the case of Ms. M, the exoskeleton could reduce the risk of falling by approximately $4 \%$. The various changes made to this solution would not contribute significantly to a further reduction of this risk.

\section{Discussion}

A theoretical approach is proposed for the design, evaluation and improvement of innovative solutions. Unlike other existing methods [12], our proposal focuses on the notion of risk. In representing the approach, we have established three steps for the design process: problem exploration, problem solving, and solution evaluation. In the first phase, we propose that the needs analysis integrates the identification of risks in the initial situation. This would help the design team to identify needs that have not been expressed by stakeholders. In the second phase, these risks, translated into requirements, allow the designers to propose alternative solutions and develop different intermediate design objects. Finally, in the third stage, we propose to evaluate risk perception at the same time as benefit perception in order to estimate the acceptability of the solution. We believe that the results of this evaluation may be useful for a better understanding of the situation of the problem and for improving a solution being designed. Multiple iterations between problem understanding and solution assessment could lead to a product design that will better meet the needs of the target population and be more acceptable to the market.

As part of this approach, the work carried out focused on the risks for elderly people at home.

Risk identification for a person at home implies knowing the causal factors of each risk and relating them to each other. In order to propose a model for estimating the occurrence probability of a risk, we chose one of the most recurrent and significant risks, that of falling. This risk has already been studied [31-34], but no assessment model involving various types of causal factors has been proposed.

We proposed a model for estimating the risk of falling using the Bayesian network technique. Arbelaez already used this method to evaluate the acceptability of innovation [36]. Other 


\section{L.A. Salgado et al. / Advances in Science, Technology and Engineering Systems Journal Vol. 5, No. 3, $158-165$ (2020)}

studies have used the same technique to assess the risk of falling $[38,39]$. We use this technique to estimate the risk of falling by evaluating different types of causal factors: physiological problems, cognitive impairments, social isolation, environmental maladjustment, poor living conditions and medical problems. The results are intended to contribute to the analysis of needs and the evaluation and improvement of new solutions.

We used this model with two elderly people living at home. Interviews were conducted to obtain information. Using the proposed model, we identified a probability of falling for these two individuals. The results are different for each of them. One of the differentiating factors is the fact that one of these two people has already had a fall, which has affected their mobility and lifestyle.

The risk of falling is only one of the twenty-two identified hazards that can affect the ability to keep elderly people at home. The reasoning used to assess the risk of falling can be replicated to estimate other hazards. To help older adults live well at home, health innovations aimed at reducing risk are needed.

In view of the results obtained, we have imagined the type of solutions that could be proposed to reduce this risk. In addition, in designing an innovative solution, we hypothesized the improvements that could be made to a proposal, based on the risk of falling assessment.

\section{Conclusion and Perspectives}

This study was conducted with the aim to proposing a new design approach to innovative solutions based on a risk analysis of the real situation of elderly people at home.

In addition to this approach, a risk identification model is proposed, with the purpose of estimating the probability of a person falling. This work is evaluated with a case study concerning the design of an innovative solution for mobility assistance.

The Bayesian network technique was used to build the model. The causal factors of this risk were identified and correlated to define the structure of the model. We believe that this technique could be used for the evaluation of overall risks. This should be validated in future research.

The model developed was applied with two elderly people who were interviewed and observations were made in their homes. The responses obtained were used to feed the network and to determine the probability of each person falling. Based on the high risk of falling presented by one of the people studied, an exploration of the use of these results for the design and improvement of the acceptability of the solution was conducted.

The results presented here are a first exploration of the use of the proposed model. It is important for future studies to validate this approach with a larger number of elderly people.

Further work should consist in assessing risks and benefits globally and with other stakeholders (medical staff, family members, organizations). This evaluation should focus on the development of a fall prevention solution.

When assessing the perception of benefits and risks by multiple actors, various conflicts may arise. It is important to identify and address them. Managing these conflicts could increase the acceptability of an innovative solution.
The method used to build the Bayesian network can be improved. For the construction of the probability tables, several status spaces by factor could be considered in order to obtain more precise results, rather than only yes and no. In addition, field data could be used to complement expert opinions for the definition of the probability tables in a more detailed way.

In the context of a collaborative design approach for innovations in home support for the elderly, this model can be used as a tool for understanding the problem and assisting in decisionmaking. It will enable project leaders to evaluate and improve the acceptability of a solution, right from the early stages of design.

\section{Conflict of Interest}

The authors declare no conflict of interest.

\section{References}

[1] N. Blanpain and G. Buisson, "Projections de population à l'horizon 2070 , Deux fois plus de personne de 75 ans ou plus qu'en 2013,' Paris, France, 2016.

[2] INSEE, "L'évolution de la dépendance des personnes âgées : un défi en termes de prise en charge et d'emploi", Orléans, 2012.

[3] S. Peek, "Understanding technology acceptance by older adults who are aging in place: a dynamic perspective," Ph.D Thesis, Universiteit op woensdag, 2017.

[4] F. Prate, "Evaluation des technologies pour la santé et l'autonomie : Vers un modèle transversal et modulaire. Illustration par la technologie robotique," Ph.D Thesis, Université de Nice Sophia Antipolis, 2015.

[5] A. M. Sponselee, B. Schouten, D. Bouwhuis, and C. Willems, "Smart home technology for the elderly: perceptions of multidisciplinary stakeholders," in Constructing Ambient Intelligence: AMI 2007 Workshops, Darmstadt, Germany, 2007. https://doi.org/10.1007/978-3-540-85379-4_37

[6] G. Arbelaez Garces, E. Bonjour, and A. Rakotondranaivo, "Towards a method for acceptability analysis: Application to healthcare innovation," in International Conference on Engineering, Technology and Innovation: Engineering Responsible Innovation in Products and Services (ICE 2014), Bergamo, Italy, 2014. https://doi.org/10.1109/ICE.2014.6871583

[7] L. Acosta-Salgado, A. Rakotondranaivo, and E. Bonjour, "Innovation acceptability in elderly care: a risk evaluation approach," in IEEE International Conference on Engineering, Technology and Innovation (ICE/ITMC), Sophia-Antipolis, France, 2019. https://doi.org/ 10.1109 /ice.2019.8792564

[8] S. Cleary and T. Malleret, Risques. perception, évaluation, gestion : Une approche positive des risques globaux auxquels sont confrontés les décideurs. Maxima, 2006.

[9] L. Acosta-Salgado, L. Morel, and I. Verilhac, "Towards a better understanding of the concept of design," Proj. / Proyéctica / Proj., 2(20), 91-114, 2018. https://doi.org/10.3917/proj.020.0091

[10] N. Skiba, "Processus d'innovation centré sur l'utilisateur: identification des besoins et interprétation de données issues de l'intégration de l'utilisateur dans le processus de co-conception," Ph.D Thesis, Université de Lorraine, 2014.

[11] Carine Lallemand and G. Gronier, Méthodes de design UX, EYROLLES, 2016

[12] H. BEN Rejeb, V. Boly, and L. Morel, “A new methodology based on kano model for the evaluation of a new product acceptability during the frontend phases," in IEEE International Computer Software and Applications Conference, $\quad$ Turku, $\quad$ Finland, 2008 https://doi.org/10.1109/COMPSAC.2008.94

[13] M. Fishbein and I. Ajzen, Belief, Attitude, Intention, and Behavior: An Introduction to Theory and Research, Addison-We, 1975.

[14] I. Ajzen, "The Theory of Planned Behavior," Organ. Behav. Hum. Decis. Process., 50(2), 179-211, 1991. https://doi.org/10.1016/07495978(91)90020-T

[15] F. D. Davis, “A technology acceptance model for empirically testing new end-user information systems: Theory and results," Ph.D Thesis, Massachusetts Institute of Technology, 1986.

[16] H. Taherdoost, "A review of technology acceptance and adoption models and theories," in 11th International Conference Interdisciplinarity in Engineering, INTER-ENG 2017, Tirgu Mures, Romania, 2017. 
https://doi.org/10.1016/j.promfg.2018.03.137

[17] Y. Tanaka, M. Kitayama, S. Arai, and Y. Matsushima, "Major psychological factors affecting consumer's acceptance of food additives: Validity of a new psychological model," Br. Food J., 117(11), 2788-2800, 2015. https://doi.org/10.1108/BFJ-02-2015-0062

[18] A. Bearth, M. E. Cousin, and M. Siegrist, "The consumer's perception of artificial food additives: Influences on acceptance, risk and benefit perceptions," Food Qual. Prefer., 38, 14-23, 2014. https://doi.org/10.1016/j.foodqual.2014.05.008

[19] J. Choi, A. Lee, and C. Ok, "The effects of consumers' perceived risk and benefit on attitude and behavioral intention: a study of street food," J. Travel Tour. Mark., 30(3), 222-237, 2013. https://doi.org/10.1080/10548408.2013.774916

[20] M. S. Featherman and P. A. Pavlou, "Predicting e-services adoption: A perceived risk facets perspective," Int. J. Hum. Comput. Stud., 59(4), 451474, 2003. https://doi.org/10.1016/S1071-5819(03)00111-3

[21] D. Delignières, "Risque préférentiel, risque perçu et prise de risque," In : Cognition et performance [online], Paris, France, 1993. https://doi.org/10.4000/books.insep.1419.

[22] S. Vandentorren et al., "August 2003 heat wave in France: Risk factors for death of elderly people living at home," Eur. J. Public Health, 16(6), 583591, 2006. https://doi.org/10.1093/eurpub/ck1063

[23] M. D. L. Á. Vázquez-Sánchez, M. D. C. Gastelu-Cantero, and J. L. CasalsSánchez, "Valoración de las necesidades de los ancianos que viven solos en una zona básica de salud," Enferm. Clin., 18(2), 59-63, 2008. https://doi.org/10.1016/S1130-8621(08)70699-5

[24] S. e. Carter, E. m. Campbell, R. w. Sanson-Fisher, S. Redman, and W. j. Gillespie, "Environmental hazards in the homes of older people," Age Ageing, 26(3), 195-202, 1997. https://doi.org/ 10.1093/ageing/26.3.195

[25] A. E. Stuck, J. M. Walthert, T. Nikolaus, C. J. Büla, C. Hohmann, and J. C. Beck, "Risk factors for functional status decline in community- living elderly people: a systematic literature review," Soc. Sci. Med., 48(4), 445469, 1999. https://doi.org/ 10.1016/s0277-9536(98)00370-0

[26] C. Berr, F. Balard, H. Blain, and J. Robine, "Vieillissement l'émergence d'une nouvelle population," Med. Sci., 28(3), 281-287, 2012. https://doi.org/10.1051/medsci/2012283016

[27] H. J. Swift, D. Abrams, R. A. Lamont, and L. Drury, "The risks of ageism model: how ageism and negative attitudes toward age can be a barrier to active aging," Soc. Issues Policy Rev., 11(1), 195-231, 2017. https://doi.org/10.1111/sipr.12031

[28] S. Clement, C. Rolland, and C. Thoer-Fabre, Usage, normes, autonomie : Analyse critique de la bibliographie concernant le vieillissement de la population, Puca, 2007.

[29] M. E. Tinetti, C. Gordon, E. Sogolow, P. Lapin, and E. H. Bradley, "Fallrisk evaluation and management: challenges in adopting geriatric care practices," Gerontologist, 46(6), 717-725, 2006. https://doi.org/10.1093/geront/46.6.717

[30] M.-L. Gaubert-Dahan, A. Cougnaud-petit, L. De Decker, C. Annweiler, O. Beauchet, and G. Berrut, "Essai de modélisation des facteurs de risque de chute chez les sujets âgés," Ger Psychol Neuropsychiatr Vieil, 9(3), 277285, 2011. https://doi.org/10.1684/pnv.2011.0289

[31] R. Rajagopalan, I. Litvan, and T. P. Jung, "Fall prediction and prevention systems: Recent trends, challenges, and future research directions," Sensors, 17(11), 1-17, 2017. https://doi.org/10.3390/s17112509

[32] C. A. Pfortmueller, G. Lindner, and A. K. Exadaktylos, "Reducing fall risk in the elderly: risk factors and fall prevention, a systematic review," Minerva Med., 105(4), 275-281, 2014

[33] B. Leclerc et al., "Risk factors for falling among community-dwelling seniors using home-care services: An extended hazards model with timedependent covariates and multiple events," Chronic Dis. Can., 28(4), 111$120,2008$.

[34] L. Z. Rubenstein, "Falls in older people: epidemiology, risk factors and strategies for prevention," Age Ageing, 35(2), 37-41, 2006. https://doi.org/10.1093/ageing/afl084

[35] D. Galvez Manriquez, "Evaluation de la capacité à innover : Une approche par auto évaluation et suivi supporté par des analyses multicritères dynamiques," Ph.D Thesis, Université de Lorraine, 2015.

[36] G. Arbelaez Garces, A. Rakotondranaivo, and E. Bonjour, "An acceptability estimation and analysis methodology based on Bayesian networks," Int. J. Ind. Ergon., 53, 245-256, 2016. https://doi.org/10.1016/j.ergon.2016.02.005

[37] P. Naïm, P.-H. Wuillemin, P. Leray, O. Pourret, and A. Becker, Réseaux Bayésiens, 3e edition, Eyrolles, 2007.

[38] G. Koshmak, M. Linden, and A. Loutfi, "Dynamic Bayesian networks for context-aware fall risk assessment," Sensors, 14(5), 9330-9348, 2014. https://doi.org/ 10.3390/s140509330

[39] H. Wang, M. Li, J. Li, J. Cao, and Z. Wang, “An improved fall detection approach for elderly people based on feature weight and Bayesian classification," in 2016 IEEE/ICMA International Conference on Mechatronics and Automation, 2016 https://doi.org/10.1109/ICMA.2016.7558609

[40] American Geriatrics Society, "Guideline for the Prevention of Falls in Older Persons," J. Am. Geriatr. Soc., 49(5), 664-672, 2002. https://doi.org/10.1046/j.1532-5415.2001.49115.x

[41] P. J. Fos and C. L. McLin, "The risk of falling in the elderly: A subjective approach," Med. Decis. Mak., 10(3), 195-200, 1990. https://doi.org/10.1177/0272989X9001000306

[42] HAS (Haute Autorité de Santé), "Évaluation et prise en charge des personnes âgées faisant des chutes répétées," Paris, 2009.

[43] S. Q. Qu and J. Dumay, "The qualitative research interview", 8(3), 2011 https://doi.org/ 10.1108/11766091111162070

[44] L. Garreau and P. Romelaer, Méthodes de recherche qualitatives innovantes. Economica, 2019. 